\title{
Review of High Temperature Superconductors and Application in Various Fields
}

\author{
Sumit Kumar Gupta ${ }^{1 *}$, Harish Jangam ${ }^{2}$ and Nipun Sharma ${ }^{2}$ \\ ${ }^{1}$ Department of Physics, India \\ ${ }^{2}$ Research Scholars, India \\ *Corresponding author: Sumit Kumar Gupta, Assistant Professor, Department of Physics, Jaipur, India

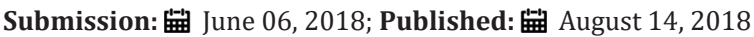

Abstract

The layered perovskite cuprate materials are a unique class of superconductors with unusual normal-state and superconducting properties. The common physics to all these materials is that of the underlying $\mathrm{CuO}_{2}$ planes. This review provides a survey of and guide to their physical properties as it relates to the superconductivity of this interesting group of conducting oxides. The present statuses on applications of cuprate based high-temperature superconductors have been included. In this paper, all characteristics of cuprate based superconductors depending upon the recent discoveries and applications of those compounds have been included and explained so that a researcher can get a good idea about this field easily. The article gives a summary of the prevailing arguments of researchers to relate the material to cuprates and the comparative features of many families of superconductors.

Keywords: Superconductors; Cuprate-based superconductors; Applications

\section{Introduction}

The discovery of superconductivity in 1911 came as the result of straightforward research to investigate the microscopic source of the electrical resistance of metals: Studies on alloys and temperature dependent measurements had evidenced that this could be decreased by reducing the density of impurity atoms as well as by lowering temperature. Mercury with its exceptionally low melting and boiling temperatures offered the best perspectives with respect to very low impurity levels. Heike Kamerlingh Onnes had built at the University of Leiden a unique cryogenic facility where he was able to achieve substantially lower temperature than any other laboratory. This led him in 1911 to his famous experiment to see how low one can go concerning electrical resistance. The observed sudden jump to apparently zero resistivity below $4 \mathrm{~K}$ came nevertheless as a big surprise. Kamerlingh Onnes immediately recognized it as indication of a new state of matter. In 1933, the discovery of Walter Meißner and Robert Ochsenfeld that magnetic fields are expelled from a superconductor, demonstrated that superconductivity is a true thermodynamical state since in contrast to the situation for a merely perfect conductor this expulsion is independent of the experimental history (Figure 1).

Soon after mercury, Kamerlingh Onnes expanded the list of SC materials to include tin $(3.7 \mathrm{~K})$ and lead $(7.2 \mathrm{~K})$. After the discovery of superconductivity in thallium $(2.4 \mathrm{~K})$ and indium $(3.4 \mathrm{~K})$ again in Leiden, Meißner successfully continued the search through the periodic table finding in 1928 tantalum (4.2K), 1929 thorium $(1.4 \mathrm{~K})$ and 1930 titanium $(0.4 \mathrm{~K})$, vanadium $(5.3 \mathrm{~K})$ and niobium, the element with the highest critical temperature $\mathrm{T}_{c}=9.2 \mathrm{~K}$. The extension to binary alloys and compounds in 1928 by de Haas and Voogd was fruitful bringing in $\mathrm{SbSn}, \mathrm{Sb}_{2} \mathrm{Sn}, \mathrm{Cu}_{3} \mathrm{Sn}$ and $\mathrm{Bi}_{5} \mathrm{Tl}_{3}$. $\mathrm{Bi}_{5} \mathrm{Tl}_{3}$ and shortly afterwards a $\mathrm{Pb}$-Bi eutectic alloy established first examples of critical magnetic field values in the Tesla range (Figure 2).

\section{Cuprate High-Temperature Superconductors Materials}

\section{YBCO material}

The unit cell of YBCO is based on a stack of three perovskite cells as shown in Figure 3 and the lattice type is either tetragonal or orthorhombic, depending on the oxygen content. The central perovskite cell contains a $\mathrm{Y}$ atom, sandwiched between $\mathrm{CuO}_{2}$ planes. Adjacent to the $\mathrm{CuO}_{2}$ planes are layers of $\mathrm{BaO}_{2}$ and at the top and bottom of the cell there are $\mathrm{Cu}-\mathrm{O}$ chains which have variable oxygen content, dependent upon the overall oxygenation level of the material [1-10].

The HTS compounds can be described using a four-number naming scheme, the numbers representing: 


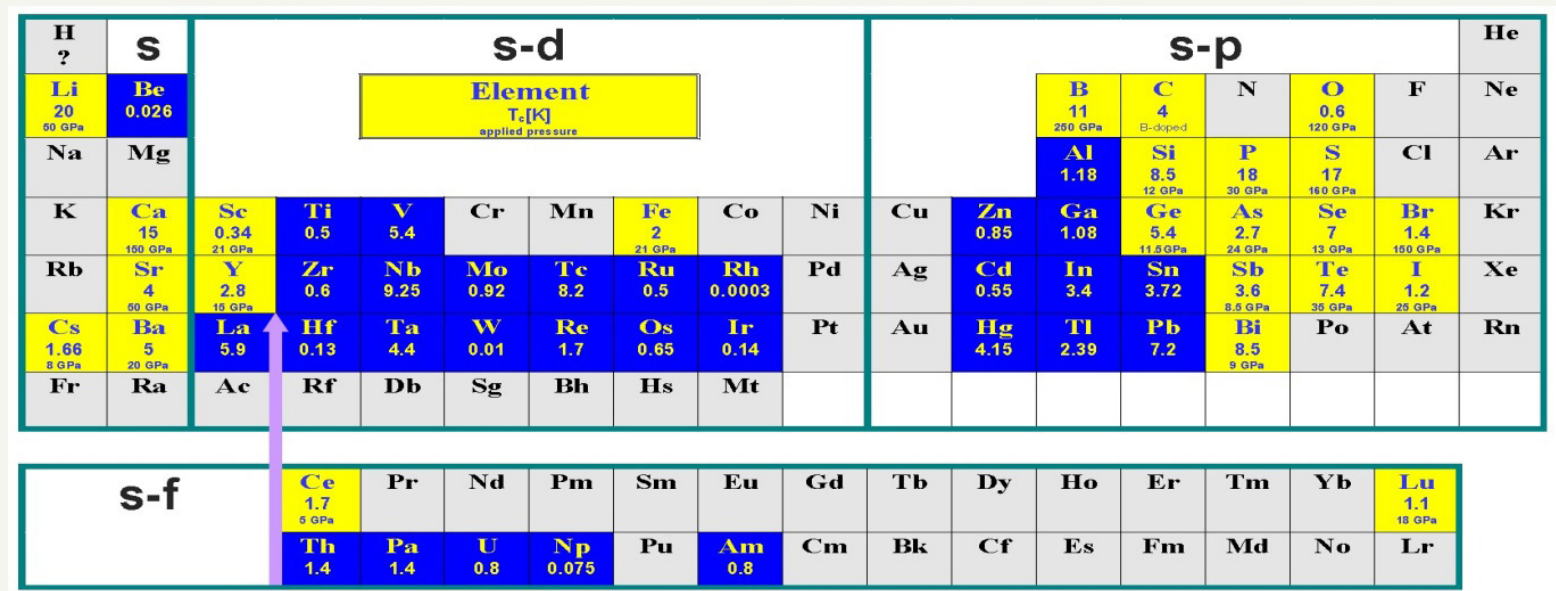

Figure 1: Periodic table with the distribution and Tc $[\mathrm{K}]$ of the chemical elements for which superconductivity has been observed with or without application of pressure.

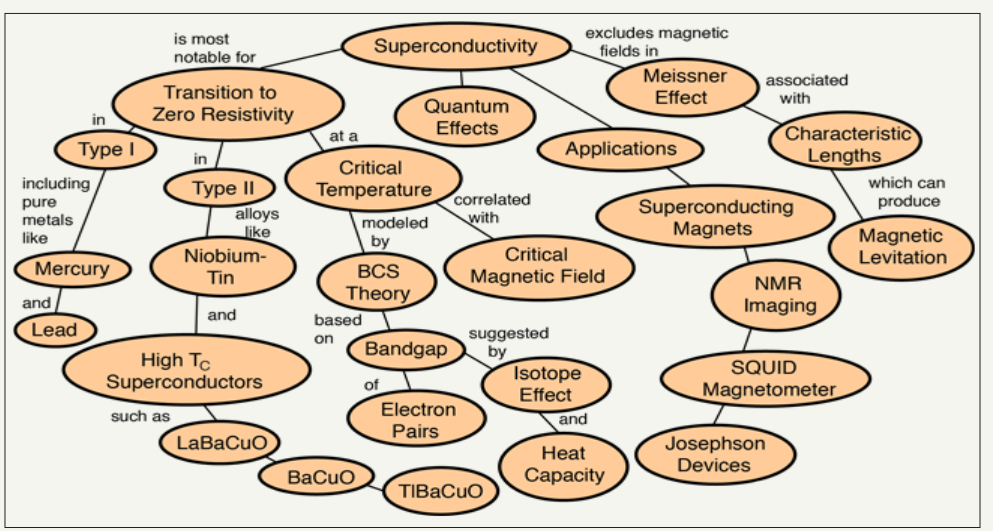

Figure 2

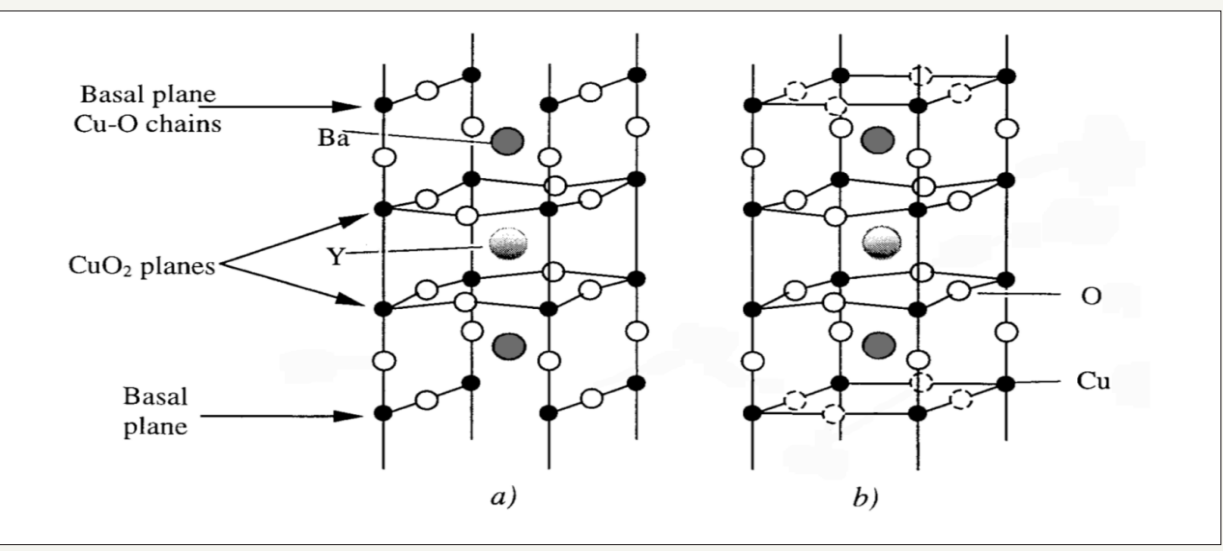

Figure 3: Unit cell of a) $\mathrm{YBa} 2 \mathrm{Cu} 3 \mathrm{O} 7$ and b) $\mathrm{YBa} 2 \mathrm{Cu} 3 \mathrm{O} 7-\delta$. The dashed circles indicate oxygen sites which are partially filled.

A. The number of insulating layers between $\mathrm{CuO}_{2}$ planes (for YBCO, 1, the basal plane)

B. The number of spacing layers between blocks of $\mathrm{CuO}_{2}$ planes (for $\mathrm{YBCO}, 2$, the $\mathrm{BaO}_{2}$ layers)

C. The number of separating layers within each block of $\mathrm{CuO}_{2}$ planes (for YBCO, 1, the Y layer)
D. The number of $\mathrm{CuO}_{2}$ layers in each block (for YBCO, 2)

Thus, the crystal structure may be represented as in Figure 4. Each square based pyramid has $\mathrm{O}$ atoms at its apices and a $\mathrm{Cu}$ atom at the centre of the base. The square $\mathrm{Cu}-\mathrm{O}$ sheets have an $\mathrm{O}$ atom at each corner and $\mathrm{a} \mathrm{Cu}$ atom at the centre. Note that in order to show two complete blocks of $\mathrm{CuO}_{2}$ planes, the origin of Figure 4 is shifted by $(0,0,1 / 2)$ relative to the conventional cell shown in Figure 3 . 
The variation of the oxygen content in $\mathrm{YBa}_{2} \mathrm{Cu}_{3} \mathrm{O}_{7-\delta}$ is extremely important in determining the superconducting properties. The effect of reducing the oxygen content below 7 atoms per unit cell is shown in Figure 5. An optimum $\mathrm{T}_{c}$ of $93 \mathrm{~K}$ is obtained for $\delta=0.08$, but if more oxygen is removed from the structure, $\mathrm{T}_{\mathrm{c}}$ falls rapidly and for $\delta>0.56, \mathrm{YBa}_{2} \mathrm{Cu}_{3} \mathrm{O}_{7-\delta}$ is not superconducting. Also important for the superconducting properties of YBCO is the existence of chains of $\mathrm{Cu}-\mathrm{O}$ atoms, which have metal-like electrical properties and reduce the anisotropy of the superconductor.

The variation of the unit cell parameters of YBCO with oxygen content is shown in Figure 6 , which demonstrates the tetragonal-orthorhombic transition at around $\delta=0.6$. Although the superconducting phase of YBCO is orthorhombic, in practice it is not possible to distinguish a and b directions in a macroscopic sample due to twinning on a fine scale.

The large anisotropy of the crystal structure has consequences for the physical properties as the effective mass of the electrons moving in the $a-b$ plane, $m_{a b}$, is different from that in the $c$ direction, $\mathrm{m}_{c}$. This difference is characterized by an anisotropy parameter, $\gamma$, such that $\gamma^{2}=\mathrm{m}_{\mathrm{c}} / \mathrm{m}_{\mathrm{ab}}$. The anisotropy parameter is a measure of the ratio of the coherence length and the penetration depth in the $a-b$ plane and c-direction. For YBCO, $\gamma$ is approximately 5-7 as demonstrated by the values shown in Table 1 .

Table 1: Anisotropy of $\xi$ and $\lambda$ in YBCO (T=0K).

\begin{tabular}{|c|c|c|}
\hline & $\begin{array}{c}\text { Coherence Length, } \xi \\
\text { (nm) }\end{array}$ & $\begin{array}{c}\text { Penetration Depth, } \boldsymbol{\lambda} \\
\text { (nm) }\end{array}$ \\
\hline a-b Plane & 2 & 140 \\
\hline $\begin{array}{c}\text { c Direc- } \\
\text { tion }\end{array}$ & 0.3 & 900 \\
\hline
\end{tabular}

The large Ginzburg-Landau parameter $(\kappa=\lambda / \xi)$ means that YBCO is very strongly type II. The lower critical field $\mathrm{B}_{c 1}$ is around $10 \mathrm{mT}$ at $77 \mathrm{~K}$ compared with an upper critical field $\mathrm{B}_{\mathrm{c} 2}$ of over $800 \mathrm{~T}$ for field in the c-direction at $\mathrm{T}=0 \mathrm{~K}$.

Table 3: Classification and reported optimized Tc values of cuprate HTS compounds.

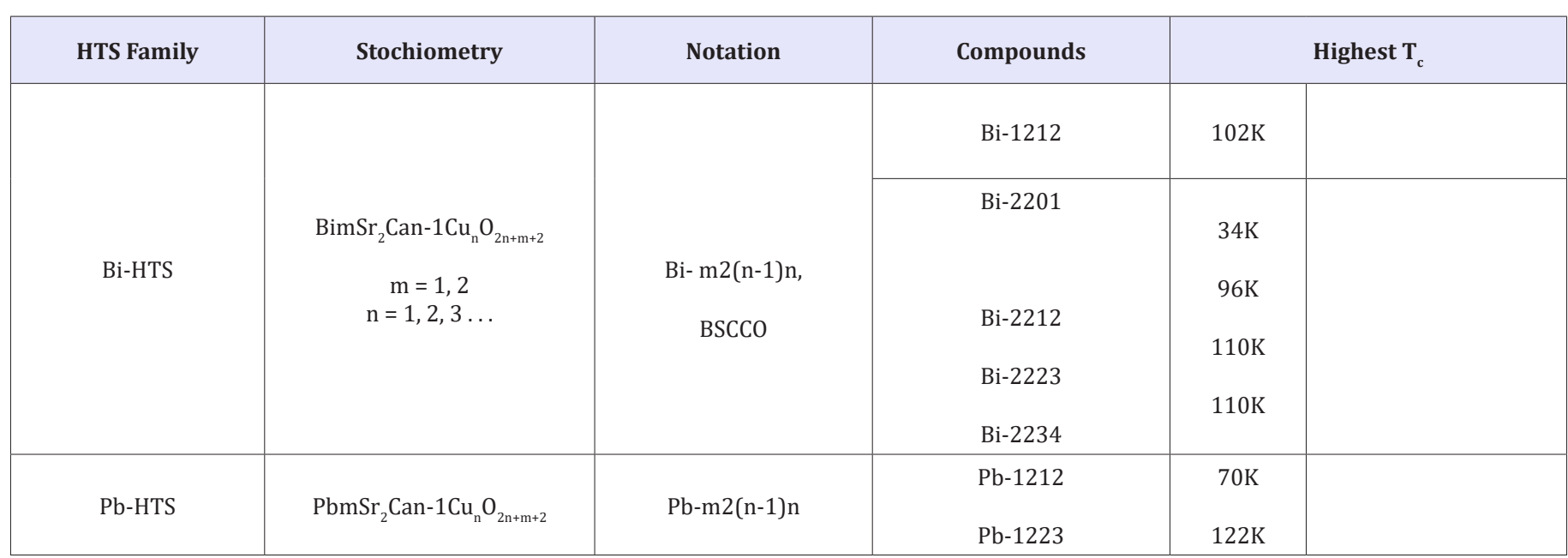

\section{BSCCO material}

The superconducting compounds of $\mathrm{Bi}-\mathrm{Sr}-\mathrm{Ca}-\mathrm{Cu}-\mathrm{O}$ are based on $\mathrm{Bi}_{2} \mathrm{Sr}_{2} \mathrm{Ca}_{\mathrm{n}} \mathrm{Cu}_{\mathrm{n}+1} \mathrm{O}_{6+2 n}$, where $\mathrm{n}$ is an integer. The structures of the $\mathrm{n}=1$ and $\mathrm{n}=2$ compounds, generally known as Bi-2212 and Bi-2223 are shown in Figure 7. BSCCO-2223 is an extremely anisotropic material, the value of $\gamma$ being at least an order of magnitude greater than that in YBCO. Values of the coherence length and penetration depth are difficult to measure accurately and there is significant variation in the data reported in the literature, though some estimates are given in Table 2 [11-15].

Table 2: Anisotropy of $\xi$ and $\lambda$ in BSCCO $(\mathrm{T}=0 \mathrm{~K})$.

\begin{tabular}{|c|c|c|}
\hline Coherence Length & Penetration Depth, $\boldsymbol{\xi}(\mathbf{n m})$ & $\boldsymbol{\lambda} \mathbf{( n m})$ \\
\hline BSCCO-2212 a-b 3 300 & BSCCO-2212 & c 0.4500 \\
\hline BSCCO-2223 a-b & BSCCO-2223 & c 0.04 \\
\hline
\end{tabular}

\section{Thallium and mercury-based compounds}

There are several families of superconducting materials which incorporate $\mathrm{Tl}$. The $\mathrm{Tl}_{2} \mathrm{Ba}_{2} \mathrm{Ca}_{\mathrm{n}} \mathrm{Cu}_{\mathrm{n}+1} \mathrm{O}_{2 \mathrm{n}+6}$ system is analogous to the $\mathrm{Bi}$ based material with equivalent crystal structures and similar inter-layer spacings. In addition, the 'single Tl-O layer' $\mathrm{TlBa}_{2} \mathrm{Ca}_{\mathrm{n}}$ ${ }_{1} \mathrm{Cu}_{\mathrm{n}} \mathrm{O}_{2 \mathrm{n}+3}$ and $\mathrm{TlSr}_{2} \mathrm{Ca}_{\mathrm{n}-1} \mathrm{Cu}_{\mathrm{n}} \mathrm{O}_{2 \mathrm{n}+3}$ are superconducting. The $\mathrm{n}=1$ and $\mathrm{n}=2$ structures are shown in Figure 8.

The TSCCO compounds can be difficult to synthesis unless the $\mathrm{Tl}$ is partially substituted by $\mathrm{Pb}$ or $\mathrm{Bi}$ and the critical temperatures are generally lower than those of TBCCO, although they may be increased to $100 \mathrm{~K}$ with appropriate doping. The superconducting properties of the $\mathrm{Tl}$ compounds are less sensitive to oxygen stoichiometry than YBCO and in terms of anisotropy, they lie somewhere between YBCO and BSCCO. Of all the high $\mathrm{T}_{c}$ materials fabricated to date, those with the highest transition temperatures are the $\mathrm{Hg}$ based compounds. $\mathrm{HgBa}_{2} \mathrm{Ca}_{2} \mathrm{Cu}_{3} \mathrm{O}_{8}$, which has the same crystal structure as $\mathrm{Tl}-1223$, has a $\mathrm{T}_{c}$ of $135 \mathrm{~K}$, which can be increased by application of pressure. Due to the fact that the $\mathrm{Hg}$ compounds are closely related to the $\mathrm{Tl}$ materials in terms of their crystal structures, they have similar superconducting properties crystal struc 


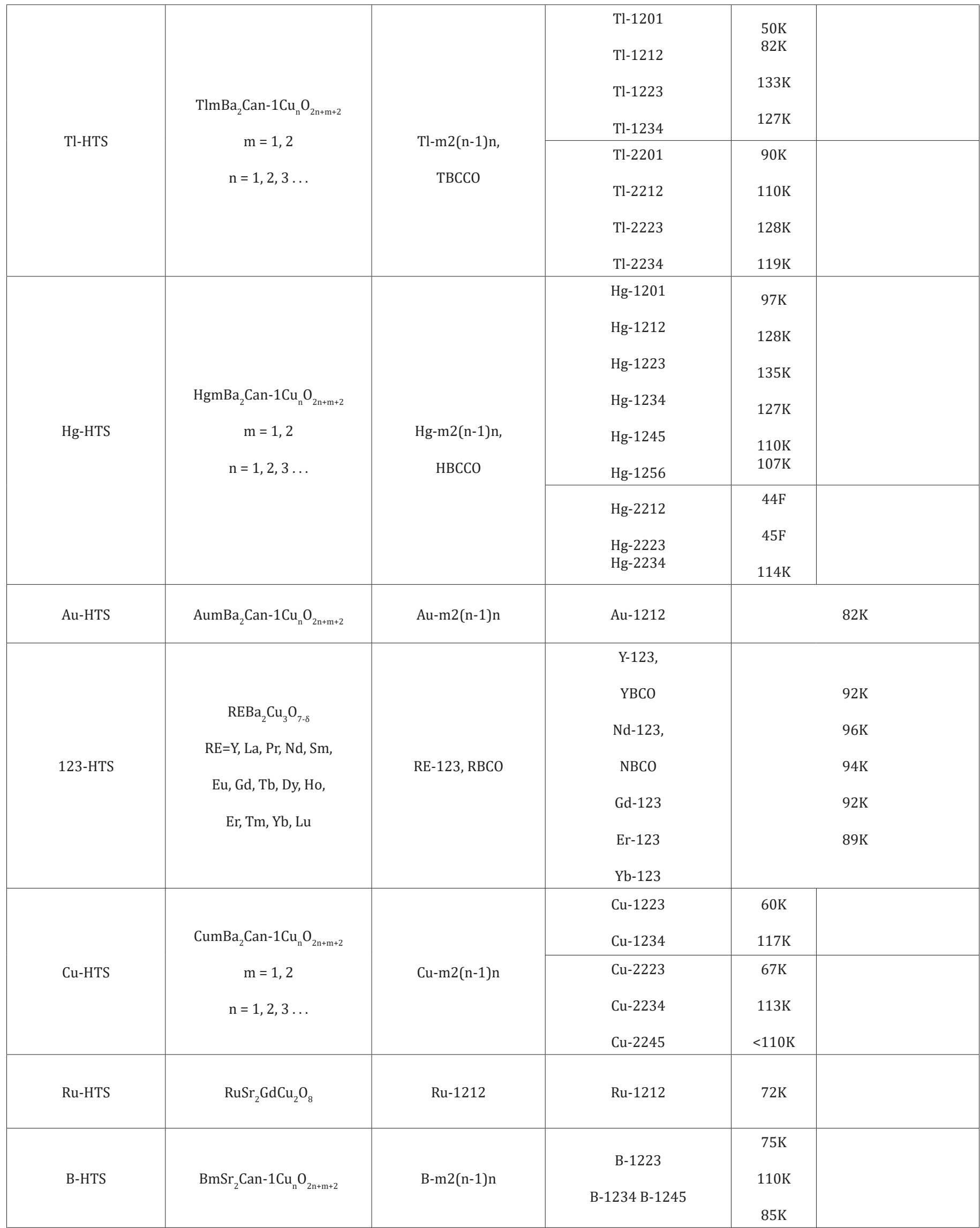




\begin{tabular}{|c|c|c|c|c|c|}
\hline \multirow{3}{*}{ 214-HTS } & \multirow[b]{2}{*}{$\mathrm{E}_{2} \mathrm{CuO}_{4}$} & $\begin{array}{l}\text { LSCO } \\
\text { “0201“ }\end{array}$ & $\mathrm{La}_{2-\mathrm{x}} \mathrm{Sr}_{\mathrm{x}} \mathrm{CuO}_{4} \mathrm{Sr}_{2} \mathrm{CuO}_{4}$ & $\begin{array}{c}51 \mathrm{~K} \\
25(75) \mathrm{K}\end{array}$ & \\
\hline & & $\begin{array}{l}\text { Electron-Doped HTS } \\
\text { PCCO } \\
\text { NCCO }\end{array}$ & $\begin{array}{c}\mathrm{La}_{2-\mathrm{x}} \mathrm{Ce}_{\mathrm{x}} \mathrm{CuO}_{4} \\
\mathrm{Pr}_{2} \mathrm{Ce}_{\mathrm{x}} \mathrm{CuO}_{4} \\
\mathrm{Nd}_{2-\mathrm{ex}} \mathrm{CuO}_{4} \\
\mathrm{Sm}_{2-\mathrm{ex}} \mathrm{CuO}_{4} \mathrm{Eu}_{2-\mathrm{ex}} \mathrm{CuO}_{4}\end{array}$ & & $\begin{array}{l}28 \mathrm{~K} \\
24 \mathrm{~K} \\
24 \mathrm{~K} \\
22 \mathrm{~K} \\
23 \mathrm{~K}\end{array}$ \\
\hline & $\mathrm{Ba}_{2} \mathrm{Ca}_{\mathrm{n}-1} \mathrm{Cu}_{\mathrm{n}} \mathrm{O}_{2 \mathrm{n}+2}$ & $" 02(n-1) n "$ & $\begin{array}{l}\text { “0212“ “0223“ } \\
\text { “0234“ “0245“ }\end{array}$ & & $\begin{array}{r}90 \mathrm{~K} \\
120 \mathrm{~K} \\
105 \mathrm{~K} \\
90 \mathrm{~K}\end{array}$ \\
\hline Infinite-Layer HTS & $\mathrm{ECuO}_{2}$ & Electron-Doped I. L. & $\mathrm{Sr}_{1-\mathrm{x}} \mathrm{La}_{x} \mathrm{CuO}_{2}$ & & $43 \mathrm{~K}$ \\
\hline
\end{tabular}

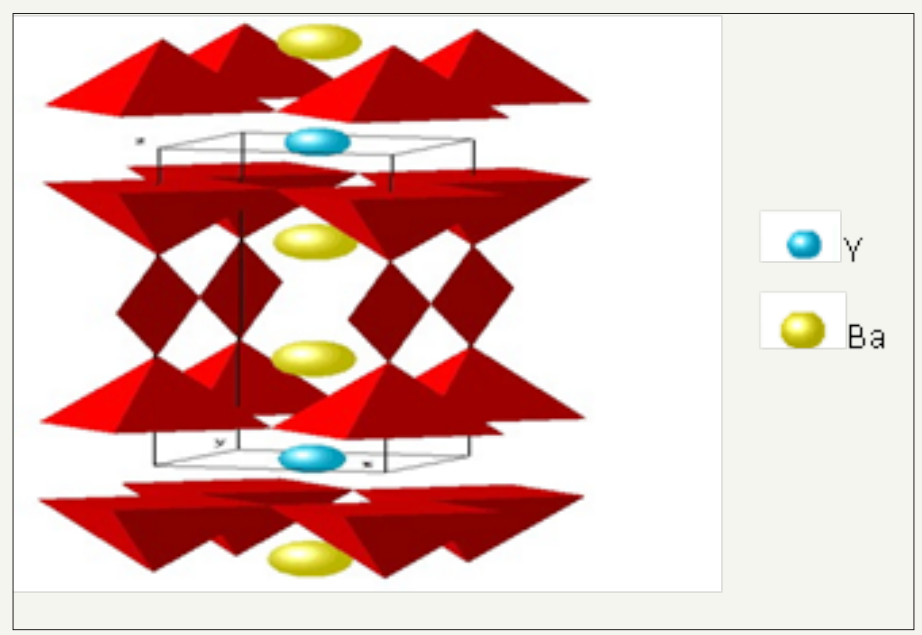

Figure 4: The crystal structure of $\mathrm{YBCO}$. The pyramids have $\mathrm{O}$ atoms at the apices and $\mathrm{Cu}$ atoms at the centre of the base.

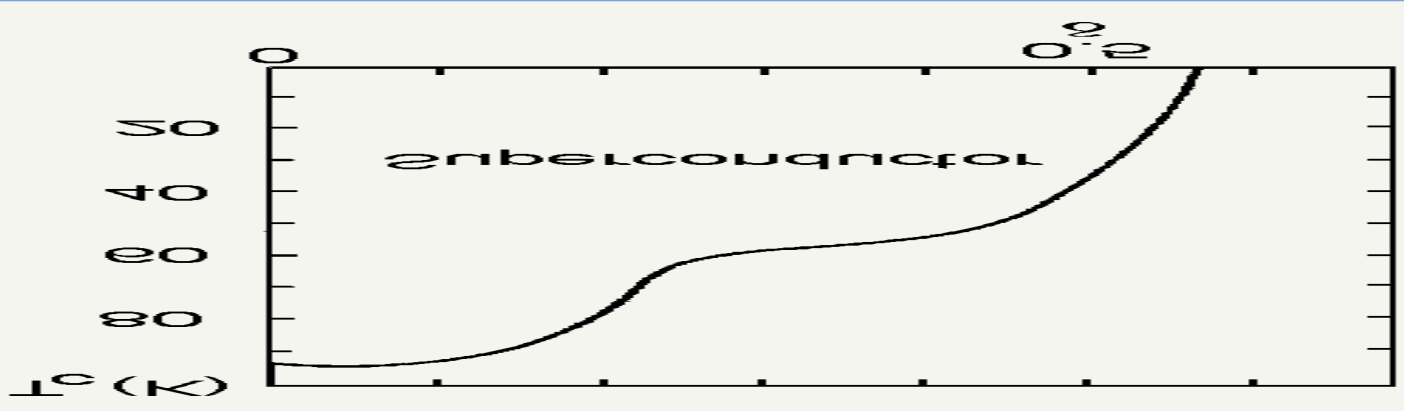

Figure 5: The effect of oxygen content on the Tc of $\mathrm{YBa} 2 \mathrm{Cu} 3 \mathrm{O} 7-\delta$.

\section{Application of High Temperature Superconductors}

\section{Electric power}

Several applications of superconductivity in the electric power sector have undergone extensive evaluation and even prototype development: e.g., fusion magnets, generators, superconducting magnetic

energy storage (SMES), and AC transmission lines. An overview of the impact of superconductivity on these applications is provided in Table 1 other applications not discussed here include magneto 
hydrodynamic power generation, transformers, motors, and power conditioning electronics.

\section{Fusion magnets}

Magnetic fusion requires confinement of a heated plasma in a magnetic field long enough to get it to Ignite-about 1 second. *O Superconducting magnets are considered essential for the continuous, high field operation that would be necessary for a commercial fusion reactor. Like particle accelerator magnets,
Federal fusion magnet programs have provided a significant government market that has driven the development of superconducting magnet technology. As a result, there are no major unsolved technical problems in the fabrication of large fusion magnets. The lack of follow through on these programs can be attributed to technical, economic, and political issues affecting fusion technology. Because magnet refrigeration costs are less than 1 percent of total construction costs, the advent of HTS is not expected to change the outlook for fusion.

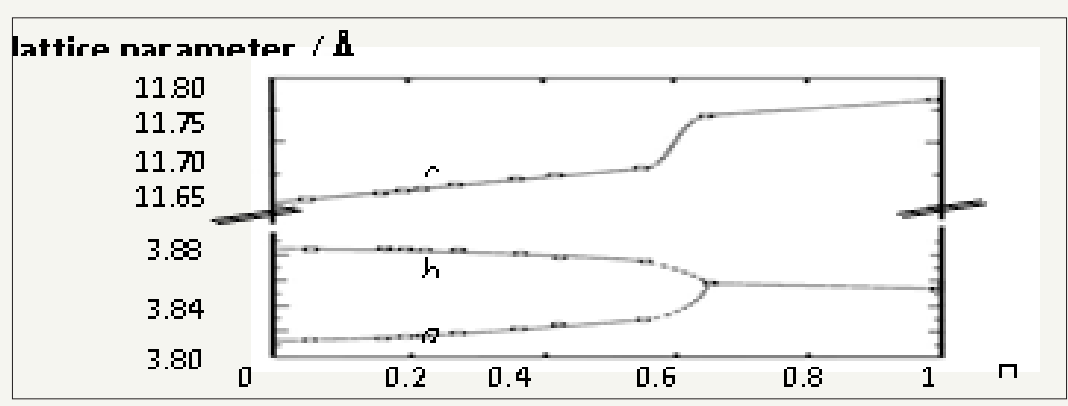

Figure 6: The unit cell parameters of $\mathrm{YBCO}$ as a function of the oxygen content.

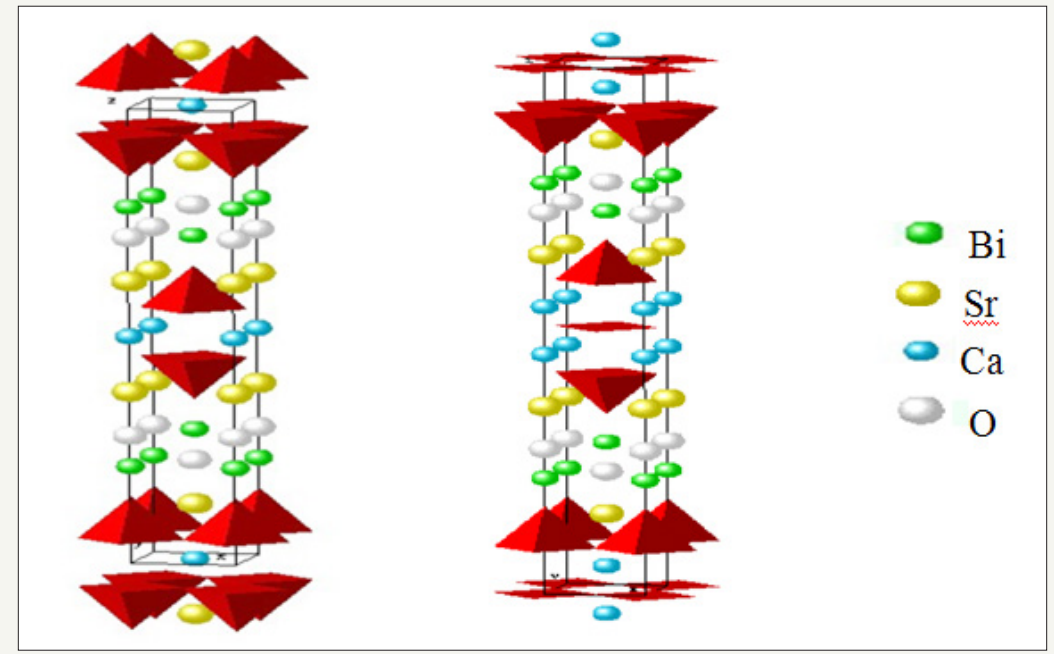

Figure 7: The crystal structures of Bi-2212 and Bi-2223.

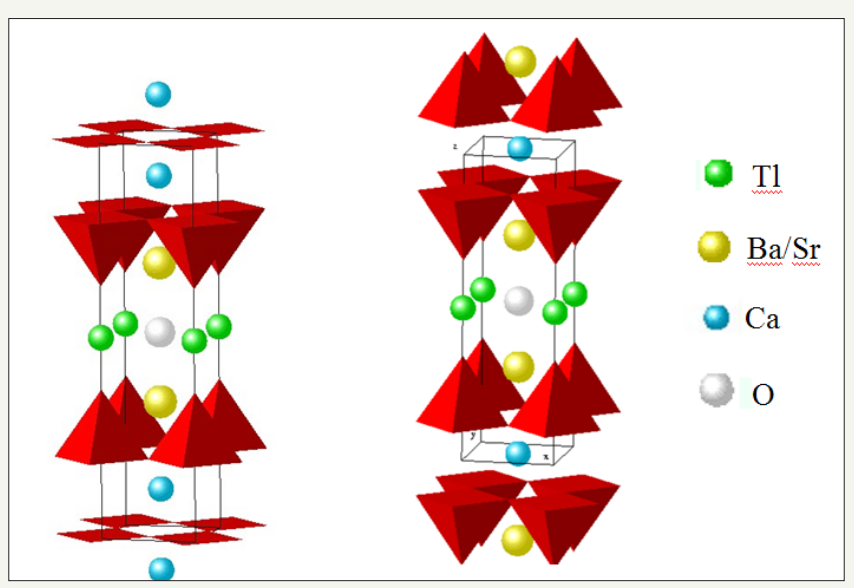

Figure 8: Crystal structures of 1212 and 1223. 


\section{Superconducting generators}

Superconducting generators enjoy three potential benefits over conventional generators. They offer better system stability against frequency changes due to transients on the grid. Because they can operate at higher magnetic fields ( 5 to 6 tesla), the size can be reduced up to 50 percent; this in turn could reduce capital costs significantly. Finally, efficiency could be increased by 0.5 percent (a reduction in losses of around 50 percent). Even this small efficiency increase could result in fuel savings that would pay back the capital costs of the generator over its lifetime [14]. Although several prototype superconducting generators were designed and constructed at the Massachusetts institute of technology, general electric Co., and Westinghouse Electric Corp. during the 1960s to the early 1980s [15], these were never commercialized because there was no perceived demand for new generating capacity.lb Today, the United States has no significant ongoing commercial LTS generator program, although programs are continuing in West Germany, Japan, and the Soviet Union. Siemens in West Germany is proceeding with plans for an 850 megawatt (MW) commercial system, and tests of prototype components are expected to begin in 1990 [16,17]. A consortium of Japanese companies is developing a $200 \mathrm{MW}$ generator for the late 1990s Most studies indicate that LTS generators are only competitive with conventional generators at very high-power ratings (500 to $1,000 \mathrm{MW}$ ). But with low load growth in the 1980s and continuing uncertainties about demand in the 1990s, there appears to be little enthusiasm among U.S. firms to put up their own cash for R\&D on such large machines. In principle, use of HTS could make smaller machines more competitive, but estimates differ on how much. The refrigeration system would be much simpler, and this would lead to greater reliability and maintainability. But the application involves a high-field, highcurrent, wire-wound magnet, spinning at high speed, under large centrifugal stresses. HTS wires would have to carry current densities on the order of $100,000 \mathrm{Amps} / \mathrm{cm}^{2}$ in a 5 -tesla magnetic field to realize the large decrease in size possible.

These requirements make the generator one of the most difficult applications for HTS. Beyond the turn of the century, there will be a market for new generators, both to replace older equipment and to accommodate growth in demand [18-20]. The share of superconducting generators in this market is uncertain. But one thing is clear. Because it is likely to take at least 15 years to demonstrate a commercial system, the United States is effectively conceding this market to its competitors unless it restarts its LTS generator programs immediate.

\section{Superconducting magnetic energy storage (SMES)}

In an SMES system, electric power is stored in the magnetic field of a large superconducting magnet and can be retrieved efficiently at short notice. Power conditioning systems are required to convert the DC power in the magnet to AC for the grid when discharging the SMES, and vice versa when recharging. SMES has several potential applications in electric utilities. Large units (above 1GW-hr capacity) could be used for diurnal storage and load leveling. Smaller units may provide a number of operating benefits: e.g., spinning reserve, automatic generation control, black start capability, and improved system stability. SMES is also of interest to the military because it can deliver large quantities of pulsed power to weapon systems such as ground-based lasers for ballistic missile defense. The Strategic Defense Initiative Organization (SDIO) is presently supporting the development of a 20MW-hr/400MW engineering test model (ETM), which could begin tests by 1993 . Because the military design and the utility design are similar except for the power conditioning system (weapons must receive large amounts of power quickly and may drain the SMES in a very short time; utilities must have a constant reliable supply from which smaller amounts of power are withdrawn daily), utilities are providing a small percentage of the funding through the Electric Power Research Institute. Utilities have experimented with several methods of storing energy, including pumping water uphill to a reservoir, compressing air, and charging batteries and capacitors. SMES has several advantages over other types of energy storage systems. For load leveling, it offers a higher efficiency than any other storage technology-90 to 93 percent, compared to 70 to 75 percent for pumped hydro-and can switch back and forth between charging mode and discharging mode in a matter of milliseconds. This quick response time means that it can contribute to the stability of the utility system against transient disturbances.

The SMES concept has undergone extensive evaluation in the United States since the early 1970s. Most studies indicate that SMES for load leveling is only cost-effective at very large storage capacities, around $5000 \mathrm{MW}$-hr. Such an SMES would be physically very large, perhaps 1,000 meters in diarneter. To contain the magnetic forces on the coils, the SMES must be buried in bedrock, with total construction costs estimated to be around $\$ 1$ billion.

I-ITS does not appear to offer dramatic reductions in capital or operating costs for SMES. With excellent HTS materials (comparable in cost and properties to $\mathrm{NbTi}$, except with higher critical temperature), one could reduce capital costs by 3 to 8 percent. HTS would provide only marginal improvements in the efficiency of the system, since only 2 percent of the power is consumed by refrigeration (this decreases with increasing SMES capacity), and 3 to 4 percent of the power is lost in the power conversion electrical system, the main required could be another stumbling block for HTS. To reduce capital costs of the conductors, high critical current densities are required-in excess of $300,000 \mathrm{Amps} / \mathrm{cm}^{2}$. The best present HTS wires are only capable of some tens of thousands of Arnps $/ \mathrm{cm}^{2}$ at $77 \mathrm{~K}$, and this decreases in increasing magnetic fields. HTS materials could, however, be a good choice for the power leads connecting the liquid nitrogen jacket to the liquid helium temperature SMES coil.

In the present economic environment, utilities find such a large SMES unattractive compared with supplementary gas turbines. Before investing in such a large project, utilities will require that the technical feasibility and economic assumptions be demonstrated in smaller SMES systems such as the SDIO ETM mentioned above. 
Small SMES units (less than 100 MW-hr) are also undergoing evaluation for industrial or residential use in Japan.

\section{Power transmission lines}

Interest in superconducting power transmission lines dates back to the 1960s, when demand for electricity was doubling every 10 years. There was great concern about where large new power plants could be sited safely-especially nuclear plants-and about how such large amounts of power could be transmitted to users without disrupting the environment. Overhead lines often cut swathes through wooded areas and spoil scenery. Underground lines, a solution to environmental concerns, have other problems. Conventional underground cables are about 10 times more expensive than overhead lines, and consequently account for only 1 percent of the transmission lines in the United States. Moreover, because of heat dissipation and line impedance problems, these lines are limited to small capacities Superconducting lines promised to address these problems: since their current-carrying capacity is not limited by heat dissipation they are able to carry large amounts of power at relatively low voltage. After the oil embargo of 1973, the emphasis shifted to the conservation potential of superconducting transmission. On average, about 4 percent of the electric power carried by a transmission line is lost due to resistance. In principle, most of these losses could be avoided using superconducting transmission lines.

Superconducting transmission lines could carry either direct current (DC) or alternating current (AC). DC lines are used to carry large blocks of power from one point to another. A superconducting DC cable could carry very high currents with no resistive losses. But because the cost of DC lines is dominated by the conversion to $\mathrm{AC}$ at either end, a superconducting line would have to be extremely long (perhaps several hundred miles) to be economically competitive with cheaper overhead lines. Such cables are unlikely to be used except where alternatives are not available (e.g., for undersea power transmission), and are not considered further here. During the 1970s, there were several important studies of AC superconducting transmission lines. Three major projects were initiated in the United States, the most extensive of which was at Brookhaven National Laboratory. The Brookhaven project produced two 115 meter, 80 kilovolt $(\mathrm{kV})$, one-phase lines made from $\mathrm{Nb3Sn}$.

\section{Industrial applications}

There are many potential applications of superconductivity in industrial equipment. A partial list includes sensors for process and quality control; magnets for separation of solid, liquid, and gaseous mixtures; magnets for processing and shaping materials; accelerator magnets for x-ray lithography of microelectronic chips; and windings for industrial motors. In several of these applications, e.g., magnetic separation and compact accelerators, the feasibility has been demonstrated with LTS.

\section{Sensors}

Industrial sensor applications of superconductors have been discussed by several authorsm and include applications both inside and outside the factory: for example, inspection of raw materials, monitoring of manufacturing functions such as the positioning of the work piece and tool, nondestructive inspection in finished parts, detection of corrosion in bridges, or exploration for mineral and oil deposits, etc.

The most commonly discussed superconducting sensors are Superconducting Quantum Interference Devices (SQUIDS), which can detect extremely small magnetic fields; however, superconducting sensors can also be configured to measure small currents, voltages, temperature changes, and electromagnetic radiation emissions. Of course, there are numerous options for sensors using more conventional technologies: optical, chemical, ultrasonic, etc., and superconducting sensors may offer advantages only in certain niches. Heretofore, LTS SQUIDS have not found application in industrial settings because their sensitivity typically far exceeds the ambient magnetic field noise levels, and because of the difficulty of working with liquid helium. Although HTS SQUIDS operating at $77 \mathrm{~K}$ are inherently noisier than LTS SQUIDS operating at $4 \mathrm{~K}$, their sensitivity is likely to be more than adequate for the industrial environment, and they would be far easier to maintain and transport.

\section{Medical applications}

Medical applications of superconductivity are relatively recent, having their origins in research conducted during the 1970s. Examples are magnetic resonance imaging and magneto encephalography. The feasibility of using superconductivity in these areas has been demonstrated in LTS, and indeed, superconducting MR1 magnets are now well established commercially and constitute the largest nongovernment market for superconducting wire and cable. However, the prospects for penetration of present HTS materials into these markets do not appear very promising.

\section{Magnetic resonance imaging}

Each of the various body tissues, e.g., blood, organs, vessels, and bone, exhibits a slightly different chemical environment for the hydrogen atoms contained in its constituent molecules. When a strong magnetic field is applied to the body, these chemical environments can be readily distinguished

\section{Electronics and communications}

Superconducting circuits offer several advantages over conventional semiconducting devices, including higher switching speeds, lower power dissipation, extreme detection sensitivity, and minimal signal distortion. There has been a long history of LTS R\&D in electronic devices in the United States, primarily sponsored by the Department of Defense with some support from the National Bureau of Standards.

\section{Digital devices and computers}

Digital devices are those that manipulate information with discrete levels (' 1 's or O's") rather than over a continuous range, as does an analog device. Present superconducting digital circuits rely on the on/off switching of Josephson Junctions (JJs) to create these 
discrete levels, unlike semiconductor digital circuits, which use transistors. Development of a practical superconducting transistor remains a major research goal, but such a device has not yet been invented.

Computer applications of superconductors include logic gates, memories, and interconnect. In principle, a computer based on JJs could be several times faster and 100 times smaller than present computers, though this application is somewhat speculative. Meanwhile, the same devices required for JJ computer circuits can also be used in less demanding, smaller scale applications, e.g., fast analog-to-digital converters, shift registers, and memories, as well as circuits to perform arithmetic operations.

Whereas the United States scaled back its efforts in superconducting digital devices in 1983, several Japanese laboratories continued their programs, and now have produced digital integrated circuits having as many as $24,000 \mathrm{JJ}$ s on a single chip. A prototype Japanese Josephson microprocessor was recently shown to operate at a clock speed 10 times higher, and power dissipation 500 times lower, than a comparable gallium arsenide microprocessor.

\section{Conclusion}

Experts are divided, though, as to where such devices will find application. Because many problems remain with large-scale integration of JJ circuits-particularly for high-density memorysemiconductor researchers interviewed by OTA question whether LTS JJ technology.

\section{References}

1. Buckel W, Kleiner R (2013) Supraleitung-grundlagen und anwendungen. WILEY-VCH Verlag, Weinheim, Germany.

2. Buckel W, Kleiner R (2004) Superconductivity-fundamentals and applications. WILEY-VCH Verlag, Weinheim, Germany.

3. Geballe TH (2017) Super boron. Science 293(5528): 223-224.

4. Ekimov EA, Sidorov VA, Bauer ED, Mel'nik NN, Curro NJ, et al. (2004) Superconductivity in diamond. Nature 428: 542-545.
5. Buzea C, Yamashita T (2001) Review of the superconducting properties of $\mathrm{MgB}_{2}$. Supercond Sci Techn 14: R115.

6. Goodstein D, Goodstein J (2000) Phys Perspect 2: 30.

7. Huebener R, Lübbig H (2011) Die physikalisch-technische reichsanstalt, Vieweg+Teubner-Verlag, Wiesbade, Germany.

8. Fossheim K, Sudbo A (2004) Superconductivity-physics and applications. In: Fossheim K, Sudbø A (Eds.), John Wiley \& Sons, USA.

9. Mazin II (2010) Superconductivity gets an iron boost. Nature 464: 183186.

10. Bardeen J, Cooper LN, Schrieffer JR (1957) Theory of superconductivity. Phys Rev 108: 1175.

11. (2011) BCS: 50 years. In: Cooper LN, Feldman D (Eds.), World Scientific Press, Singapore.

12. Steglich F, Aarts J, Bredl CD, Lieke W, Meschede D, et al. (1979) Superconductivity in the presence of strong pauli paramagnetism: $\mathrm{CeCu}_{2} \mathrm{Si}_{2}$. Phys Rev Lett 43: 1892.

13. Pfleiderer C (2009) Superconducting phases of f-electron compounds. Rev Mod Phys 81: 1551.

14. Little WA (1964) Possibility of synthesizing an organic superconductor. Phys Rev A 134: 1416.

15. Jérome D, Mazaud A, Ribault M, Bechgaard K (1980) Superconductivity in a synthetic organic conductor (TMTSF) 2PF 6J Phys(Paris) Lett 41: L95-L98.

16. Jerome D, Mazaud A, Ribault M, Bechgaard K, Hebd CR (1980) Seances Acad Sci Ser B 290.

17. Saito G, Yamochi H, Nakamura T, Komatsu T, Nakashima M, et al. (1991) Recent progress in organic superconductors. Physica B 169(1-4): 372376.

18. Wosnitza J (2012) Superconductivity in layered organic metals. Crystals 2(2): 248-265.

19. Mermin ND, Wagner H (1966) Absence of ferromagnetism or antiferromagnetism in one- or two-dimensional isotropic heisenberg models. Phys Rev Lett 17(1133): 1307.

20. Bednorz JG, Müller KA (1986) Possible high Tc superconductivity in the Ba-La-Cu-0 system. Z Phys B 64(2): 189-193.
Creative Commons Attribution 4.0 International License

For possible submissions Click Here

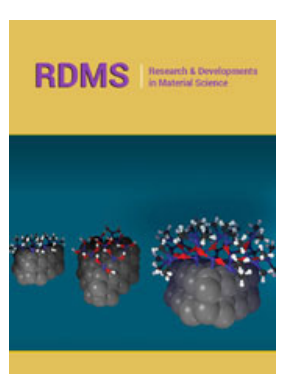

Research \& Development in Material Science Benefits of Publishing with us

- High-level peer review and editorial services

- Freely accessible online immediately upon publication

- Authors retain the copyright to their work

- Licensing it under a Creative Commons license

- Visibility through different online platforms 